\title{
Potential Advantages of a Strong-motion Velocity Meter over a Strong-motion Accelerometer
}

\author{
John F. Clinton and Thomas H. Heaton \\ Department of Civil Engineering, California Institute of Technology
}

\section{INTRODUCTION}

This study examines whether it would be better to deploy a velocity-recording strong-motion instrument in place of existing force-balance accelerometers. The proposed instrument would be comparable to a low-gain version of existing broadband seismometers. Using a large suite of Earth signals, we compare such a hypothetical long-period low-gain velocity seismometer (with a clipping level set to $\pm 5 \mathrm{~m} / \mathrm{s}$ ) with the existing \pm 2 g clipping Kinemetrics FBA-23 accelerometer.

We show that there are significant advantages in the deployment of the proposed instrument over an accelerometer:

- the velocity instrument would have several orders of magnitude greater sensitivity in the period band from $2 \mathrm{~s}$ to several hundred seconds. This would allow:

- the recording of long-period basin response from regional earthquakes as small as $M 3.0$

- the recording of teleseismic ground motions from earthquakes as small as $M 6$

which could potentially lead to dense spatial recording of small-amplitude motions that are not recorded by traditional strong-motion networks.

- furthermore, as well as allowing full recovery of ground acceleration, recovery of ground displacement is likely to be more stable from such a long-period low-gain broadband seismometer.

The most critical role of strong-motion networks is to provide on-scale recordings of potentially damaging motions over a broad frequency band. Because continuous analog recording is extremely expensive and strong shaking is infrequent, strong-motion seismographs were designed to record only during strong ground shaking. Furthermore, because of the limited dynamic range of recording devices, it was most efficient to record ground acceleration, since near-source strong ground motions have relatively flat acceleration spectra in the band from 0.3 to $3.0 \mathrm{~Hz}$.
Seismometry has seen huge advances in the past 30 years. The dynamic range of typical seismometers has increased from less than 5 orders of magnitude to more than 7, primarily because of the development of force feedback systems (Iwan et al., 1985; Wielandt and Steim, 1986; Wielandt and Streckeisen, 1982). Advances in recording systems have been even more dramatic; current 24-bit digitizers record over 7 orders of magnitude compared to the 3 orders of magnitude achievable by analog recording devices (Trifunac and Todorovska, 2001a). The past 30 years have also seen the dramatic development of digital data communication, processing, and storage, which has prompted the development of a plan for a proposed Advanced National Seismic Plan (Benz and Filson, 1998; Heaton et al., 1989). These new capabilities allow us to devise new strategies to record ground motions. In this paper we discuss potential advantages of one such strategy, deploying continuously telemetered strong-motion velocity seismometers in place of existing triggered strong-motion accelerometers. We anticipate that such a strong-motion velocity seismometer would essentially be a low-gain version of existing broadband seismometers, such as the WielandtStreckeisen STS-2. We suggest its cost would also be similar to other broadband seismometers.

A strong-motion velocity seismometer could record a broader swath of Earth motions than are currently recorded by existing strong-motion accelerometers. With a clipping level of $\pm 5 \mathrm{~m} / \mathrm{s}$ (a velocity magnitude greater than that of any seismic ground motion measured to date) it would recover on-scale all motions relevant to structural engineering, and it would record long-period motions with accelerations too small to be recorded by traditional accelerometers. We estimate that direct recording of velocity with a dynamic range of $140 \mathrm{~dB}$ would permit recording of broadband motions from regional and near-source events as small as M3.0. These broadband motions could be used to study path effects such as the amplification of long-period motions by basins. In addition, a strong-motion velocity array should be capable of recording teleseisms as small as $M 6$. This could potentially lead to dense spatial recording of small-amplitude motions that are not recorded by traditional strong-motion networks. 
Single differentiation of the raw velocity output would produce the acceleration records currently used by engineers, with the significant advantage that displacement estimates of ground motion would be obtained from a single integration of the raw data. Assuming a similar error in the true signal of velocity and acceleration, single integration would result in smaller long-period error than does a double integration. Single integration thus leads to a more stable and conclusive set of displacement time series, especially with regard to static offsets. Even very small baselines or linear trends, which are difficult to isolate and remove in current strong-motion records, can seriously distort the resultant displacement after double integration, often leaving its estimation more a matter of judgment rather than science (Boore, 2001).

We note that although resolving long-period accelerations associated with static displacements will be more stable using a long-period instrument, even small changes in tilt can significantly affect the derivation of ground displacement, as pointed out by Trifunac and Todorovsky (2001b). This is a problem common to any inertial device and so affects all instruments discussed here. To derive the translational displacements fully in the presence of tilt requires additional information from a colocated rotational meter, or a nearby true displacement meter such as GPS.

To demonstrate the increased range of Earth recordings from the proposed device, we compare this strong-motion velocity seismometer with both a typical accelerometer, the Kinemetrics FBA-23, and a broadband velocity instrument, the Wielandt-Streckeisen STS-2. The performance of each device is illustrated by showing how their dynamic characteristics relate to a wide range of seismic motions, in terms of frequency content and acceleration amplitude. To compare the instruments, we first need to describe the seismographic system, which includes a digital recording device as well as the seismometer.

\section{THE SEISMOGRAPHIC SYSTEM}

The range of amplitude and frequency recorded by a modern seismographic system is controlled by both the seismometer and the digital recorder.

\section{Dynamic Range of the Digital Recorder}

Current state-of-the-art digital recorders employ 24-bit digitizers. The nominal dynamic range of such a device is about $140 \mathrm{~dB}$. Theoretically, the dynamic range can exceed $140 \mathrm{~dB}$ at low frequencies, since low-frequency signals are oversampled and each point is the average of many samples. This dynamic range enhancement does not occur where the noise is characterized by a power density that increases as frequency decreases, i.e., some form of $1 / f$ noise. This type of noise has a constant power in frequency bands of equal relative width (Wielandt and Streckeisen, 1982). Most electronic systems, in fact, are characterized by $1 / f$ noise below $1 \mathrm{~Hz}$, and hence no resolution enhancement occurs (Joe Steim, personal communication, 2001). In practice, we find that under normal operating temperatures the dynamic range can indeed increase. For example, the Quanterra Q330, with $135 \mathrm{~dB}$ nominal dynamic range, at $26^{\circ} \mathrm{C}$ records $136 \mathrm{~dB}$ at $10 \mathrm{~Hz}$, up to $142 \mathrm{~dB}$ at $0.5 \mathrm{~Hz}$, before dropping slightly at lower frequencies (Joe Steim, personal communication, 2001). As this is not a very large difference, we will assume, for the purposes of this paper, a frequency-independent constant dynamic range of $140 \mathrm{~dB}$, approximately 7 orders of magnitude.

\section{Dynamic Range of Each Seismometer}

FBA-23

The clipping limit of the FBA-23 seismometer is $\pm 19.6 \mathrm{~m} / \mathrm{s}^{2}$ $( \pm 2 \mathrm{~g})$ up to its corner frequency of $50 \mathrm{~Hz}$. By comparing ground motions recorded simultaneously with the FBA-23 and STS-2, we were able to establish that the FBA-23 can resolve acceleration above the noise level of the instrument down to about $3 \times 10^{-6} \mathrm{~m} / \mathrm{s}^{2}$ across a broad band of frequencies $(0.01$ to $10 \mathrm{~Hz})$. This is illustrated in Figures A2 and A3 in the Appendix, which show the band-passed records of a $M 8.1$ event at $2,900 \mathrm{~km}$ epicentral distance. The FBA-23 noise at periods of about $100 \mathrm{~s}$ and $50 \mathrm{~s}$ are both of this level. For example, in Figure A3, the noise level is approximated as a sine wave with a $100 \mathrm{~s}$ period and amplitude $5 \times 10^{-5} \mathrm{~m} / \mathrm{s}$, which is equivalent to an amplitude of $3.14 \times 10^{-6} \mathrm{~m} / \mathrm{s}^{2}$ in acceleration, $136 \mathrm{~dB}$ below the clip level of $\pm 19.8 \mathrm{~m} / \mathrm{s}^{2}$. This is less than the published $145 \mathrm{~dB}$ for the frequency range 0.01 to $20 \mathrm{~Hz}$ (http://www.kinemetrics.com) but could also be due to limitations of the digitizer.

\section{STS-2}

Broadband seismometers such as the STS-2 have more complex characteristics. For seismic signals with periods shorter than the corner frequency (120 s for an STS-2), they typically have clip levels that are given in both velocity and acceleration; in the case of the STS- 2 this is $\pm 13 \mathrm{~mm} / \mathrm{s}$ and $\pm 3.3 \mathrm{~m} / \mathrm{s}^{2}$ $( \pm 0.34 \mathrm{~g})$. (Velocity clip levels are often given as peak-to-peak values; for the STS-2 this would be $26 \mathrm{~mm} / \mathrm{s}$ peak to peak, hence the $1 / 2$ peak-to-peak value is $13 \mathrm{~mm} / \mathrm{s}$.) The minimum resolved motion for the STS-2 is published in the STS-2 manual and is shown in Figure 1.

\section{Strong-motion Velocity Meter}

The hypothetical long-period, low-gain velocity instrument would have a similar type of response as the STS-2, with a corner frequency at $120 \mathrm{~s}$ and clip level at $\pm 5 \mathrm{~m} / \mathrm{s}$ and $\pm 49 \mathrm{~m} / \mathrm{s}^{2}( \pm 5 \mathrm{~g})$. Minimum resolution is assumed to be $140 \mathrm{~dB}$ below the clip level, a similar value to both the STS-2 and FBA-23.

The dynamic characteristics of these three seismometers are summarized in Table 1 and illustrated in Figure 1.

The final response of the seismographic system is similar to the instrument response, but the system dynamic range at any frequency does not exceed $140 \mathrm{~dB}$ due to the limitations 


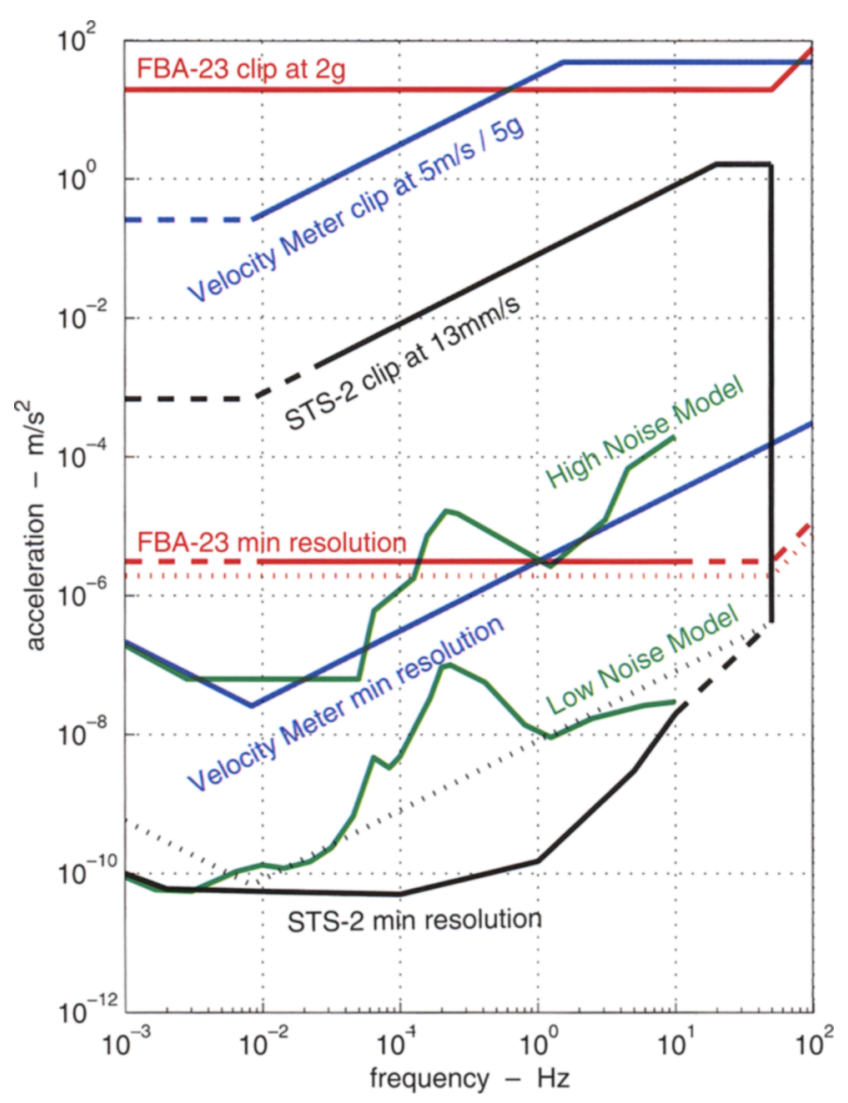

$\Delta$ Figure 1. Instrument responses in terms of acceleration. Dashed lines indicate regions of uncertain instrument response. For the FBA-23 and STS-2, dotted lines indicate areas $140 \mathrm{~dB}$ below instrument clipping levels. Noise levels are the USGS high- and low-noise models (Peterson, 1993).

of the digitizer. For the three instruments, only the system response for the STS-2 response is affected.

For brevity and simplicity, hereafter we refer to the combined seismographic system comprising both the instrument and digitizer simply as the "instrument" or the "seismometer."

\section{A COMPARISON OF INSTRUMENT CAPABILITIES USING RECORDED EARTHQUAKE SIGNALS}

We compare the hypothetical device with the Kinemetrics FBA-23 accelerometer and the Wielandt-Streckeisen STS-2 broadband velocity seismometer. To show the range of motions typically recorded on-scale and above the instrument noise of each instrument, we compare their performance in frequency and amplitude of acceleration with a broad range of Earth signals typically of interest to engineers and seismologists. We choose to measure signal strengths of each record not in the power spectra of the broadband time series, but in discrete octave-wide band-passes. This allows us to ignore the inconsistencies in the power spectra associated with arbitrarily picking a duration for the transient earthquake signals (Aki and Richards, 1980). Although we thus ignore the com-

\begin{tabular}{|lll|}
\hline \multicolumn{3}{|c|}{ Summary of Instrument Characteristics } \\
\hline Instrument Type & Free Period & Clip Level \\
\hline FBA-23 & $0.02 \mathrm{~s}(50 \mathrm{~Hz})$ & $\pm 19.6 \mathrm{~m} / \mathrm{s}^{2}( \pm 2 \mathrm{~g})$ \\
STS-2 & $120 \mathrm{~s}$ & $\begin{array}{l}\text { the smaller of } \pm 13 \mathrm{~mm} / \mathrm{s}^{2} \\
\text { and } \pm 3.3 \mathrm{~m} / \mathrm{s}^{2}( \pm 0.34 \mathrm{~g})\end{array}$ \\
& & the $\mathrm{smaller} \mathrm{of} \pm 5 \mathrm{~m} / \mathrm{s}$ and \\
Hypothetical low-gain & $120 \mathrm{~s}$ & $\pm 49 \mathrm{~m} / \mathrm{s}^{2}( \pm 5 \mathrm{~g})$ \\
seismometer & &
\end{tabular}

plexity of the overall broadband signal (and will then in general underrepresent the final strength of the record), bandpassing facilitates a better relation of the instrument limits to signal strength.

\section{Assembly of the Earthquake Database}

The earthquake signals selected were divided into magnitudedistance bins, summarized in Table 2. For each distance, the bins vary in increments of one magnitude unit. The three distance bins represent near-source, regional, and teleseismic recordings.

The records in the near-source database were generally limited to data from within $10 \mathrm{~km}$ from the projection of rupture onto the Earth's surface. Event magnitudes range from $M 7.5$ down to $M 1.5$. Records were obtained from the TriNet database (http://www.trinet.org, http://www.scecdc. scec.org/stp.html) (Hauksson et al., 2001). Due to a scarcity of data from events of $M 6$ and above, we relaxed our distance limit to records under $20 \mathrm{~km}$ from the projection of rupture. We also included data from the Southern California Earthquake Center (SCEC) Strong Motion Data Base (SMDB) (http://smdb.crustal.ucsb.edu) for historic events, with records from predominantly analog instruments, and from Taiwanese (Lee et al., 1999; Uzarski and Arnold, 2001) and Turkish (http://www.koeri.boun.edu.tr, http://www.deprem.gov.tr; Youd $e t$ al., 2000) data centers for time series from recent large earthquakes outside of Southern California.

The regional database was represented by records at a distance of about $100 \mathrm{~km}$. Event magnitudes range from $M 7.5$ down to $M$ 1.5. As with the near-source database, the distance bin was relaxed to include records within $85-110 \mathrm{~km}$ of the projection of rupture onto the Earth's surface for the sparse data sets from the larger magnitude events. The data sources were the same as those for the near-source database.

We limited records in our teleseismic database to signals recorded at about 3,000 km epicentral distance. We used data from $M 8$ to $M 6$ events, obtained from the IRIS-GSN Web site (http://www.iris.washington.edu).

Each bin contained records from a wide sampling of events and stations so that we could obtain reasonable median values of peak amplitude.

All time series from a broadband velocity recording instrument were differentiated to acceleration. 


\section{TABLE 2}

Summary of Waveform Data for Each Magnitude-distance Bin

For the teleseismic data sets, $M 8$ is represented by events in the range $M 7.6-M 8.0$, at $21^{\circ}-31^{\circ}$ and $33-480 \mathrm{~km}$ depth, with two additional records from the $M 8.2637 \mathrm{~km}$ deep-focus Bolivia event at $20^{\circ}$. M 7 is represented by events in the range $M 6.8-M 7.4$ at $23^{\circ}-29^{\circ}$ and $10-185 \mathrm{~km}$ depth. $M 6$ is represented by events all of $M 6$ at $25^{\circ}-29^{\circ}$ and $10-49 \mathrm{~km}$ depth.

\begin{tabular}{|c|c|c|c|c|c|}
\hline & Magnitude & \# Stations & \# Records & Events & Instruments-Data Source \\
\hline \multirow{10}{*}{$\begin{array}{l}\text { 1. NEAR SOURCE: } \\
\text { data within 0-20 km of } \\
\text { epicenter (or surface } \\
\text { projection of rupture) }\end{array}$} & $M 7.5$ & 26 & 78 & Chi-Chi '99 & A800, A900 Geotech—CWB Taiwan \\
\hline & & 5 & 14 & Kocaeli '99 & $\begin{array}{l}9 \times \text { SMA-1, } 5 \times \text { GSR-16-ERD and Kandilli,Tur- } \\
\text { key) }\end{array}$ \\
\hline & M6.5 & 9 & 26 & Northridge '94 & $23 \times$ SMA-1, 3 $\times$ FBA-23-UCSB \\
\hline & & 14 & 41 & Imperial Valley '79 & $38 \times$ SMA-1, $3 \times$ DCA-10—UCSB \\
\hline & & 1 & 3 & Coalinga '83 & $3 \times$ SMA-1-UCSB \\
\hline & M5.5 & 3 & 8 & 3 & $8 \times$ FBA-23-TriNet \\
\hline & M4.5 & 28 & 84 & 20 & $32 \times$ FBA-23, $52 \times$ STS-2 - TriNet \\
\hline & M3.5 & 10 & 62 & 21 & $32 \times$ FBA-23, $30 \times$ STS-2-TriNet \\
\hline & M2.5 & 12 & 108 & 35 & $108 \times$ STS-2-TriNet \\
\hline & $M 1.5$ & 8 & 42 & 12 & $42 \times$ STS-2-TriNet \\
\hline \multirow{8}{*}{$\begin{array}{l}\text { 2. REGIONAL : data } \\
\text { within } 90-110 \mathrm{~km} \text { of } \\
\text { epicenter (or surface } \\
\text { projection of rupture) }\end{array}$} & $M 7.5$ & 16 & 48 & Chi-Chi '99 & A800, A900 Geotech—CWB Taiwan \\
\hline & & 2 & 6 & Kocaeli '99 & $6 \times$ GSR-16-ERD Turkey \\
\hline & M6.5 & 4 & 12 & 2 & $12 \times$ STS-2-TriNet \\
\hline & M5.5 & 11 & 51 & 7 & $24 \times$ FBA-23, $27 \times$ STS-2-TriNet \\
\hline & $M 4.5$ & 13 & 52 & 5 & $10 \times$ FBA-23, $42 \times$ STS-2-TriNet \\
\hline & M3.5 & 13 & 96 & 23 & $96 \times$ STS-2-TriNet \\
\hline & M2.5 & 12 & 66 & 20 & $66 \times$ STS-2-TriNet \\
\hline & $M 1.5$ & 10 & 39 & 12 & $39 \times$ STS-2-TriNet \\
\hline \multirow{3}{*}{$\begin{array}{l}\text { 3. TELESEISMIC: } \\
\text { data about } 3000 \mathrm{~km} \\
\left(27^{\circ}\right) \text { from epicenter, } \\
\text { records usually } 20 \mathrm{sps} \\
\text { (or equivalent), up to } \\
1 \text { hour duration }\end{array}$} & $M 8$ & 19 & 57 & 9 & STS-1, STS-2, KS5400, KS3600—IRIS GSN \\
\hline & $M 7$ & 20 & 60 & 7 & STS-1, STS-2, KS5400, KS3600—IRIS GSN \\
\hline & M6 & 13 & 39 & 8 & STS-1, STS-2, KS5400, KS3600—IRIS GSN \\
\hline
\end{tabular}

\section{The Plot}

Once the database was assembled, each individual time series was passed through octave-wide band-pass filters. The absolute maxima of each band-pass of each record was recorded, as illustrated in Figures 2 and 3 . The maximum frequency for the band-passes for each magnitude-distance bin was determined by the Nyquist value of the time series. The minimum frequency was more subjectively chosen as the frequency where the signal intensity was similar to the background noise.

For each band-pass of a magnitude-distance bin, the geometric mean of all the absolute maxima was calculated. When combined with the geometric means from the other bandpasses in the same bin, we formed a line representing the octave-wide frequency content typical of ground motions for that bin. This is demonstrated for the $M 3.5$ at $100 \mathrm{~km}$ magnitude-distance bin in Figure 4. The frequency-amplitude lines for all the magnitude-distance bins are shown in Figure 5.
We also show the dynamic range performances of the instruments in Figure 5. The limits of the individual instruments to the broadband signals have been discussed (see Figure 1). The ground-motion data plotted have been band-pass filtered and to account for this we need to modify, or calibrate, the broadband instrument clip levels for an octavewide clip level. To do this, we first chose a number of broadband time series that were close to clipping each instrument (generally within $20 \%$ of saturation) and filtered these records in octave-wide band-passes. To calibrate the instruments, we then chose the band-pass with the highest velocity (for the broadband seismometers) or acceleration (for the FBA-23) and scaled this value by the percentage the time series in question came to clipping the instrument. The inherent uncertainty in this method was reduced by performing this for a number of records of varying spectral content. Typically this reduced the broadband clipping levels by about $50 \%$. 


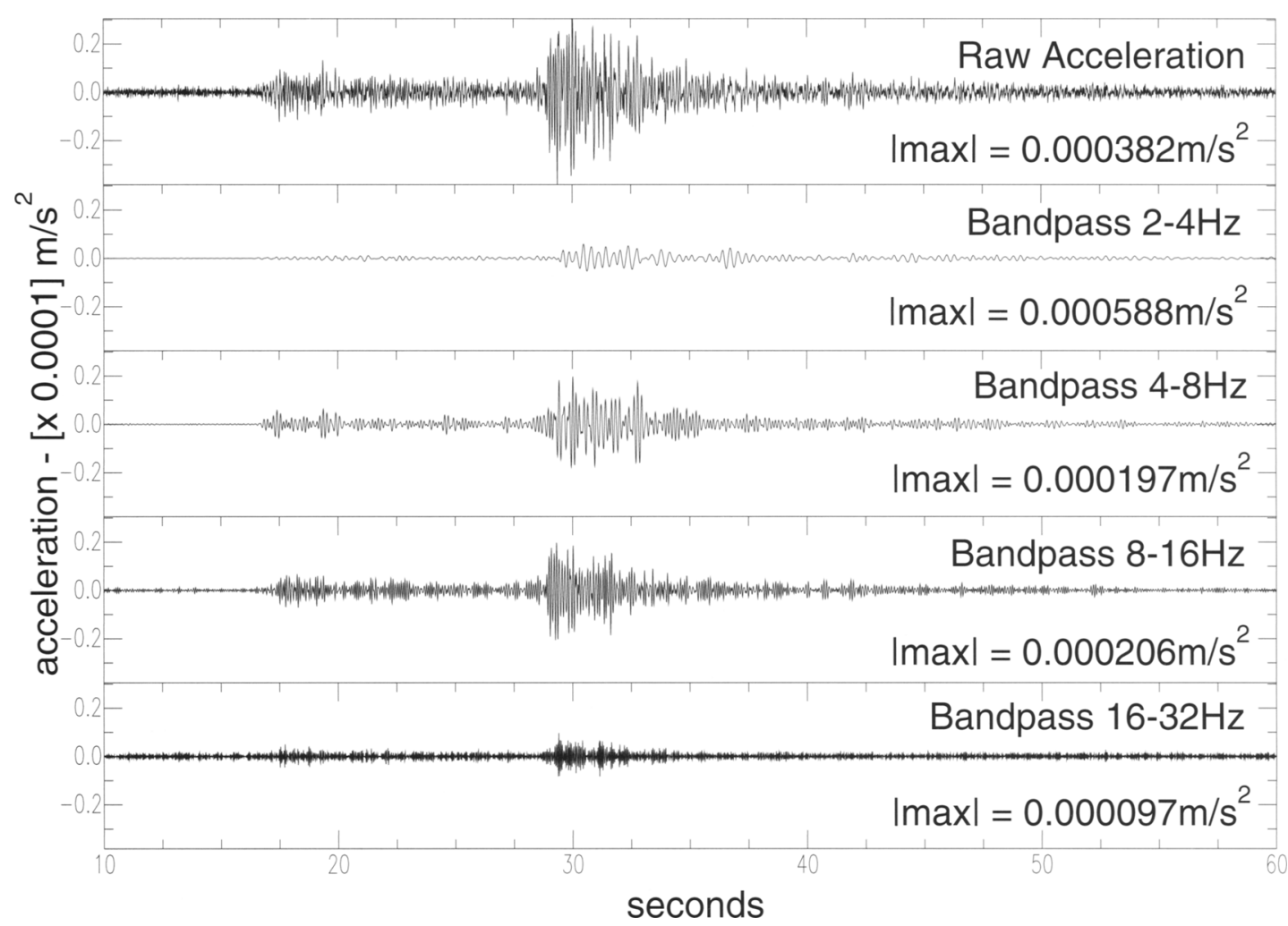

A Figure 2. Sample band-passes for M3.5 at $100 \mathrm{~km}$ (acceleration records from 3 February 1998 event, recorded at station LKL on the 80 sps north component channel of an STS-2).

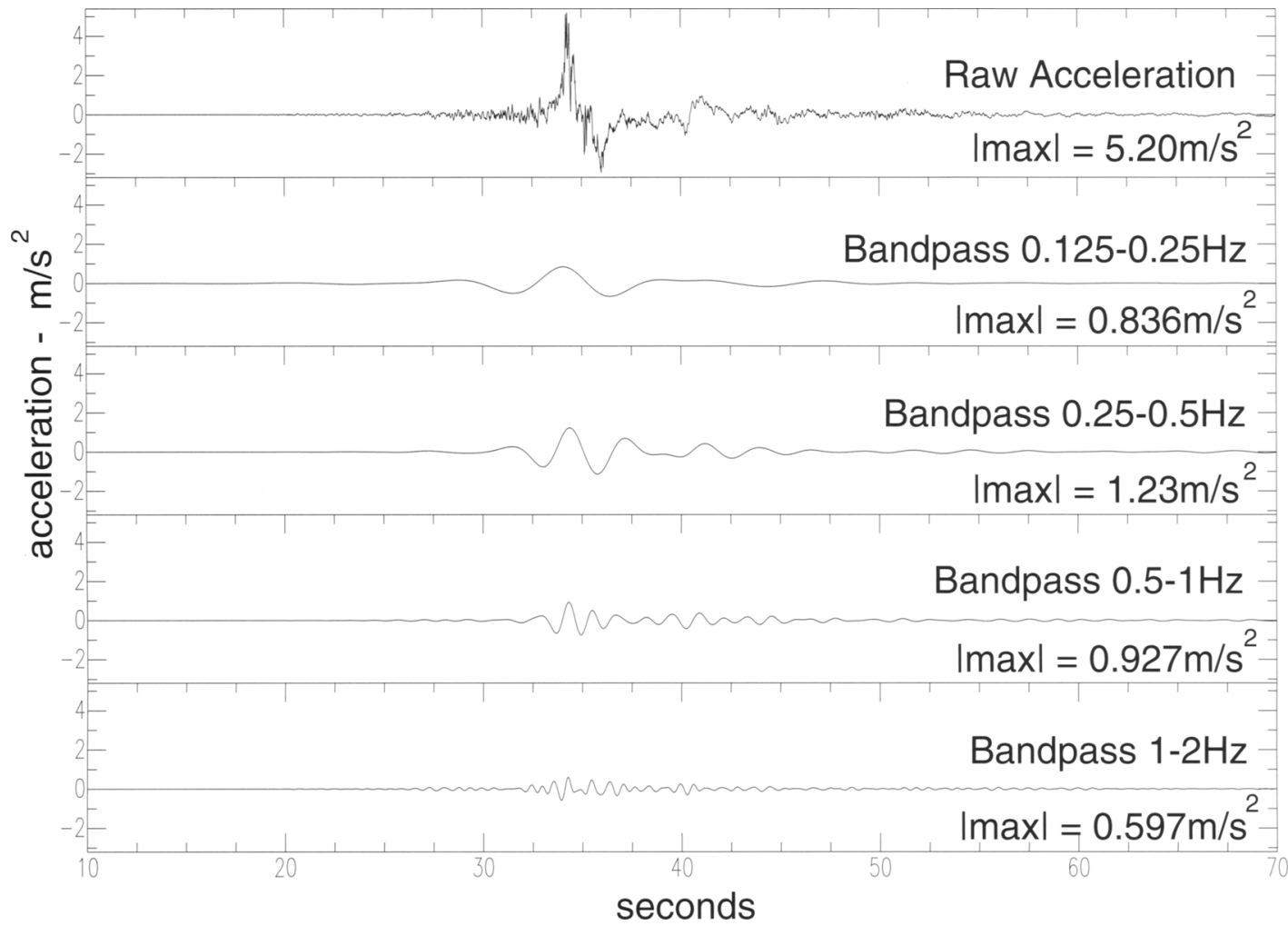

A Figure 3. Sample band-passes for M7.5 at $10 \mathrm{~km}$ (acceleration records from 21 September 1999 Chi-Chi earthquake, recorded at station T076 on the 200 sps Z component channel of a Geotech A900). 


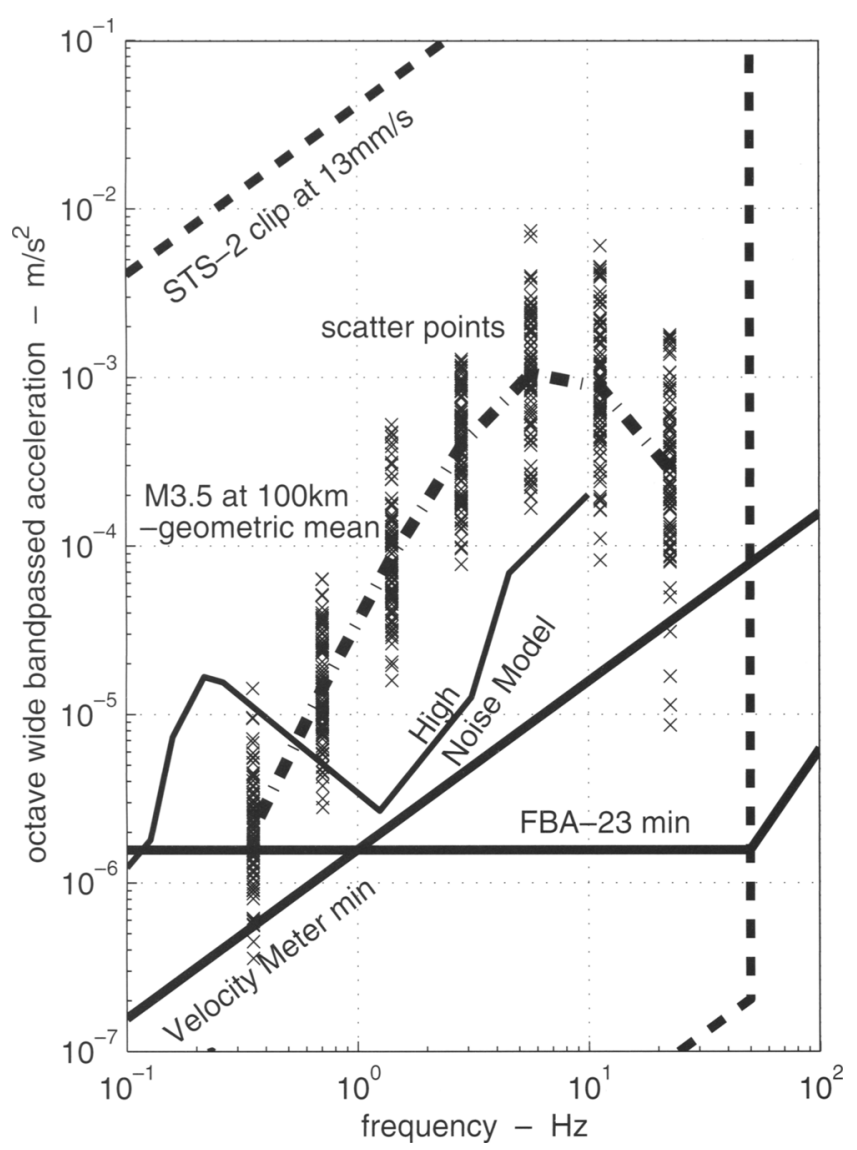

A Figure 4. Data scatter and geometric mean for $M 3.5$ at $100 \mathrm{~km}$. The crosses are the data points, and their geometric mean is represented by the thick dashed-dotted line. Instrument and noise lines are similar to Figure 1.

Finally, we superimposed the new high- and low-noise models of Peterson (1993) onto Figure 5.

The "M7.5Max" line on Figure 5 was derived from some of the largest near-source waveforms ever recorded, including data from the recent Chi-Chi, Taiwan and Kocaeli, Turkey events. The line is constructed using the absolute maxima of each band-pass for the $M 7.5$ at $10 \mathrm{~km}$ data set (not the geometric mean). It is clear that, for all these records, both the $\pm 19.6 \mathrm{~m} / \mathrm{s}^{2}$ FBA-23 and hypothetical low-gain velocity instrument are unlikely to clip in the event of most conceivable Earth motions. In this regard, both instruments would be equally effective in recording the strong-motion data gathered to date.

The yellow shading in Figure 5 indicates regions of frequency-amplitude space that can be recorded by the hypothetical instrument but are not presently recorded by the accelerometer. For the same dynamic range, the low-gain velocity instrument would record a larger range of Earth signals at periods greater than $1 \mathrm{~Hz}$ than the accelerometer. The potential of this hypothetical device for measuring longperiod motions from basin amplifications of small, local earthquakes is obvious. Teleseismic energy at longer periods, as well as energy from smaller events at teleseismic distances, would also be recorded. Regions of frequency-amplitude space presently recorded by the accelerometer but not recorded by the hypothetical instrument, are indicated by the blue shading in Figure 5.

The lines of geometric mean are not representative for some large, deep teleseismic events. The teleseismic database includes the $M 8.29$ June 1994 637-km deep-focus Bolivia event, and the median line for data from this event alone is also plotted on Figure 5. We see that its records contain interesting high-frequency energy not present at teleseismic distances during shallower events.

\section{Recovery of Acceleration}

To demonstrate the likelihood of good recovery of acceleration data from the hypothetical instrument, we present the high-frequency acceleration signals derived from a single differentiation of an STS-2 velocity time series. Figure 6 presents a comparison of acceleration records from an STS-2 and an FBA-23. The record in question, from a $M 4.5$ Northridge aftershock on 27 January 1994, recorded by the nearby TriNet station at Calabasas (CALB), had a recorded peak velocity (STS-2) of $1.24 \mathrm{~cm} / \mathrm{s}$, within $95 \%$ of clipping the instrument. We see a close correlation of these signals, even near the limit of the STS-2. We anticipate a similar capability to recover ground acceleration from the hypothetical instrument.

\section{CONCLUSIONS}

Although the existing strong-motion accelerometers generally perform well, several undesirable features of their response could be remedied by utilizing a strong-motion sensor with a better long-period response.

We have addressed two main issues. The first issue is that records from accelerographs must be integrated twice to recover ground displacement. This double integration is an unstable procedure. In order to achieve reasonable displacements we often need to apply numerous ad-hoc assumptions. The second issue is that the accelerations from long-period signals (periods longer than 10 seconds) are very small. Even with $140 \mathrm{~dB}$ of dynamic range, the signal-to-noise ratio of accelerometer records is poor for distant earthquakes. Potentially valuable basin effects from small local earthquakes are also not recorded by the current accelerometers.

We have shown that both these problems would be alleviated by employing the hypothetical instrument described here, essentially a strong-motion version of a broadband seismometer recording velocity output. The proposed instrument would better utilize the large dynamic rangescurrently up to 7 orders of magnitude - available to the instrument designer by virtue of modern 24-bit digitizers.

The seismological community would benefit from this richer range of recorded motion, as many current networks built and maintained (in mostly urban areas) by the earthquake engineering community include only strong-motion accelerometers. With the deployment of an instrument of the type discussed here, a station would record increased long- 


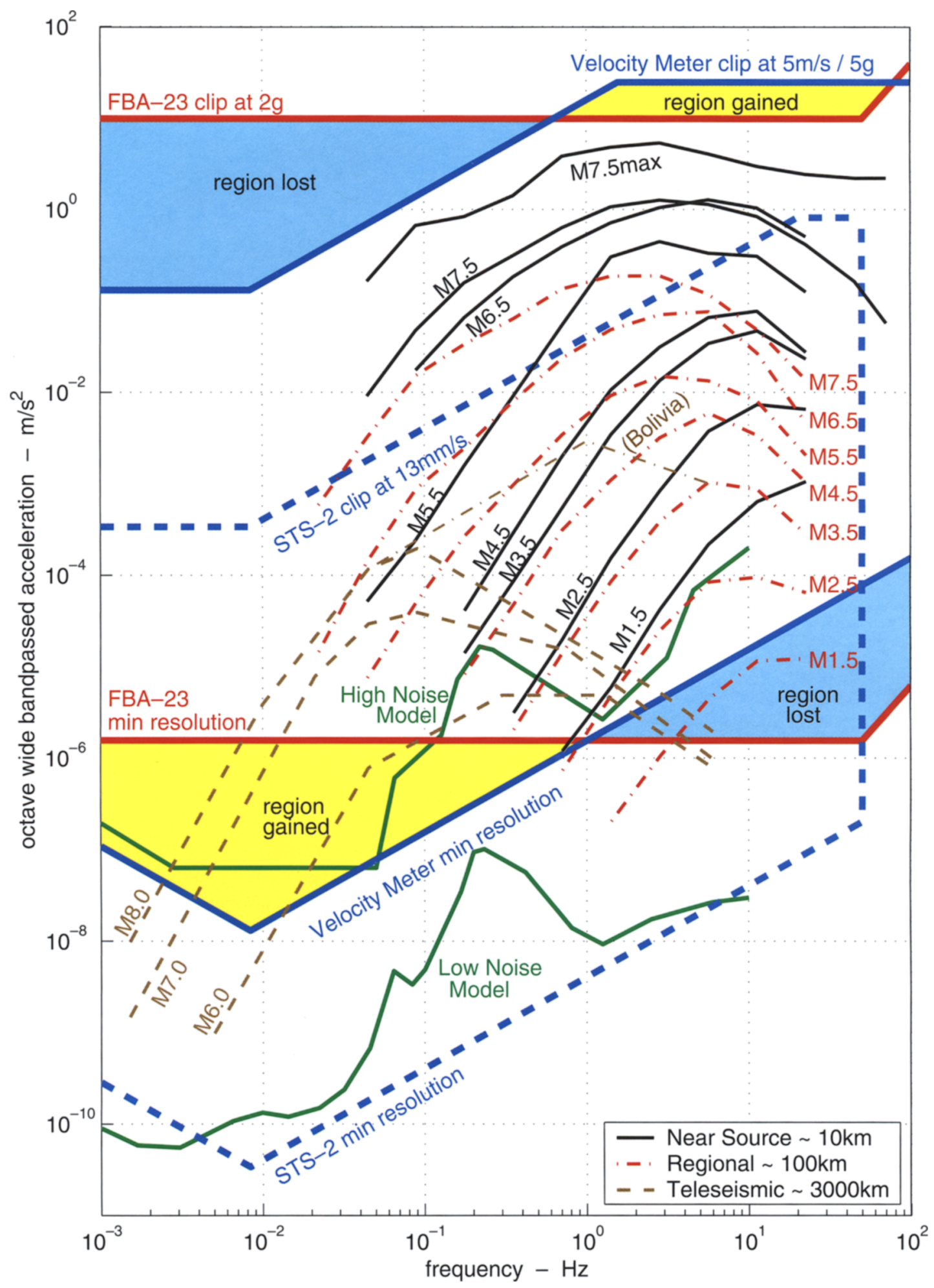

$\Delta$ Figure 5. Frequency-amplitude plot for octave-wide band-passes of ground-motion acceleration. Note that instrument limits are scaled down to account for the band-passing of the event data. Ground motions recorded on-scale by the FBA-23 lie between the solid red lines. On-scale motions recorded by the hypothetical low-gain broadband seismometer lie between the solid blue lines. The dashed blue lines give the dynamic range of the STS-2. The areas shaded light blue are regions of frequency-amplitude space that are recorded by the FBA-23 but not by the hypothetical low-gain broadband seismometer. Areas shaded yellow are regions of frequency-amplitude space that are recorded by the hypothetical low-gain broadband seismometer but not by the FBA-23. Noise levels are the USGS high- and low-noise models (Peterson, 1993). (See text for further explanation.) 


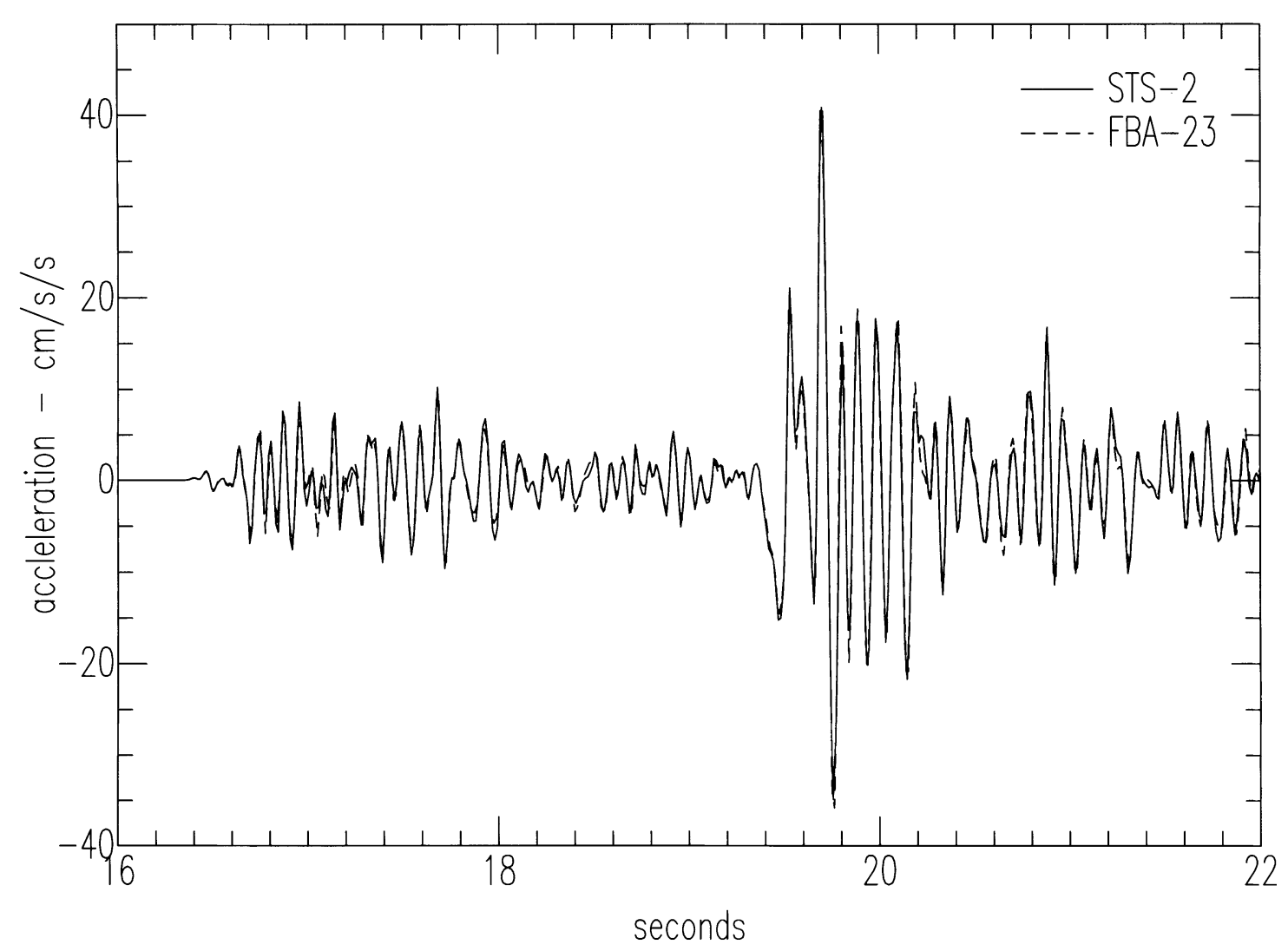

A Figure 6. Comparison of acceleration records from a differentiated STS-2 (solid line) and an FBA-23 (dashed line). The records are from a M4.5 Northridge aftershock on 27 January 1994 recorded at Calabasas (CALB), N-S component, $12 \mathrm{~km}$ from the epicenter. Time series are from 80 sps channels, with a low-pass filter at $20 \mathrm{~Hz}$.

period data from near-source events of small magnitudes, medium-sized regional events, and larger teleseisms. Continuous telemetry from a dense network of these strong-motion stations would also aid development and the eventual reliability of a future real-time earthquake early warning system.

Using our proposed instrument, the engineering community would have access to reliable estimates of near-source ground displacements without compromising the quality of acceleration records. Improved measurements of the nearsource displacement records would be of important use for the development of future structural design codes.

\section{ACKNOWLEDGMENTS}

The authors would like to thank Joe Steim, Egill Hauksson, and Susan Hough for their helpful comments and reviews.

Regional and near-source data for southern California were obtained from TriNet and the Southern California Earthquake Center (SCEC) Strong Motion Data Base (SMDB). Further regional and near-source data were obtained from the Central Weather Bureau (CWB), Taiwan, the Kandilli Observatory and Earthquake Engineering Research Institute of Bogazici University, Turkey, and the Earthquake Research Department of the General Directorate of Disaster Affairs (ERD), Turkey. Teleseismic data were obtained from the Incorporated Research Institutions for Seismology (IRIS) Data Management Center (DMC).

This research has been funded through TriNet. Funding for TriNet has been provided by the Federal Emergency Management Agency (FEMA) and the California Governor's Office of Emergency Services (OES) through the Hazards Mitigation Grant Program established following the 1994 Northridge earthquake. The required 25\% cost-sharing is provided by California Institute of Technology, California Trade and Commerce Agency, Caltrans, IDA H. L. Crotty, Verizon California, Donna and Greg Jenkins, Pacific Bell/CalREN, Southern California Edison, Sun Microsystems, Inc., Times Mirror Foundation, and others. Funding has also been provided by the United States Geological Survey from its special Northridge funds. The Southern California Earthquake Data Center (SCEDC) is also funded by the Southern California Earthquake Center (SCEC). IRIS has also provided support to TriNet.

\section{REFERENCES}

Aki, K. and P. G. Richards (1980). Quantitative Seismology: Theory and Methods, Volume 1, Freeman, San Francisco, 477-524.

Benz, H. and J. Filson (1998). Requirement for an Advanced National Seismic System, U.S. Geological Survey Circular 1188. 
Boore, D. M. (2001). Effect of baseline corrections on displacements and response spectra for several recordings of the 1999 Chi-Chi, Taiwan, earthquake, Bull. Seism. Soc. Am. 91, 1,199-1,211.

Hauksson, E., P. Small, K. Hafner, R. Busby, R. Clayton, J. Goltz, T. Heaton, K. Hutton, H. Kanamori, J. Polet, D. Given, L. M. Jones, and D. Wald (2001). Southern California Seismic Network: Caltech/USGS element of TriNet 1997-2001, Seism. Res. Lett. 72, 697-711.

Heaton, T. H., D. L. Anderson, W. J. Arabasz, R. Buland, W. L. Ellsworth, S. H. Hartzell, T. Lay, and P. Spudich (1989). National Seismic System Science Plan, U.S. Geological Survey Circular 1031.

Iwan, W. D., M. A. Moser, and C. Y. Peng (1985). Some observations on strong-motion earthquake measurement using a digital accelerograph, Bull. Seism. Soc. Am. 75, 1,225-1,246.

Lee, W. H. K., T. C. Shin, K. W. Kuo, and K. C. Chen (1999). CWD Free-field Strong-motion Data from 921 Chi-Chi Earthquake, Volume 1 (digital acceleration files on CD-ROM), Prepublication Version, Seismology Center, Central Weather Bureau, Taipei, Taiwan.

Peterson, J. (1993). Observations and modeling of background seismic noise. Open File Report 92-302, U.S. Geological Survey, Albuquerque, NM.

Streckeisen, G. and A. G. Messgerate. STS-2 Portable Very-Broad-Band Triaxial Seismometer. Dattlikonerstrasse 5, CH-8422 Pfungen, Switzerland.
Trifunac, M. D. and M. I. Todorovska (2001a). Evolution of accelerographs, data processing, strong motion arrays and amplitude and spatial resolution in recording strong earthquake motion, Soil Dynamics and Earthq. Eng. 21, 537-555.

Trifunac, M. D. and M. I. Todorovska (2001b). A note on the useable dynamic range in accelerographs recording translation, Soil Dynamics and Earthq. Eng. 21, 275-286.

Uzarski, J. and C. Arnold (editors) (2001). Earthquake Spectra: 1999 Chi-Chi, Taiwan, Earthquake Reconnaissance Report, 17(A), 5-19.

Wielandt, E. and J. M. Steim (1986). A digital very-broad-band seismograph. Annales Geophysicae 4, 227-232.

Wielandt, E. and G. Streckeisen (1982). The leaf-spring seismometer: Design and performance, Bull. Seism. Soc. Am. 72, 2,349-2,367.

Youd, T. L., J. P. Bardet, and J. D. Bray (editors) (2000). Earthquake Spectra: 1999 Kocaeli, Turkey, Earthquake Reconnaissance Report, 16(A), 65-140.

Department of Civil Engineering

Division of Engineering and Applied Science

California Institute of Technology

Pasadena, CA 91125

jclinton@caltech.edu, heaton_t@caltech.edu

\section{A Short Note on "Strong Motion" Recordings at Teleseismic Distances}

IRIS-GSN (http://www.iris.washington.edu) has 1-sampleper-second accelerometer channels (mainly FBA-23's) at many stations to record long-period data from the largest earthquakes. These events may cause motions that could overdrive the current broadband seismometers, even at teleseismic distances. Figures A1, A2, and A3 show an example of long-period motions recorded by this channel. The recordings are from station $\mathrm{SNZO}$ in New Zealand and are of the M8.1 25 March 1998 event at Balleny Island, at a distance of 2,900 km. The instruments at the station are a Geotech KS-36000-i down-hole seismometer (similar to the STS-
2) and an FBA-23. This record is within 15\% of clipping a $\pm 13 \mathrm{~cm} / \mathrm{s}$ STS-2; the earthquake actually clipped a Guralp CMG3-T (station SBA) and a Geotech/Teledyne KS-54000 (station VNDA) both set to about $\pm 9 \mathrm{~mm} / \mathrm{s}$ and both at a distance of $1,700 \mathrm{~km}$ in Antarctica. It is clear from the records that the FBA-23 is capable of recording the event well out to periods up to about 50 seconds. This clearly shows the usefulness of the strong-motion instrument at the IRIS-GSN stations, especially in the event of a great $M 9$ earthquake, which could clip the high-gain broadband instruments for great distances. A low-gain velocity recording device would be ideally suited to deployment in future IRIS-GSN stations, as well as in the proposed Advanced National Seismic System. 


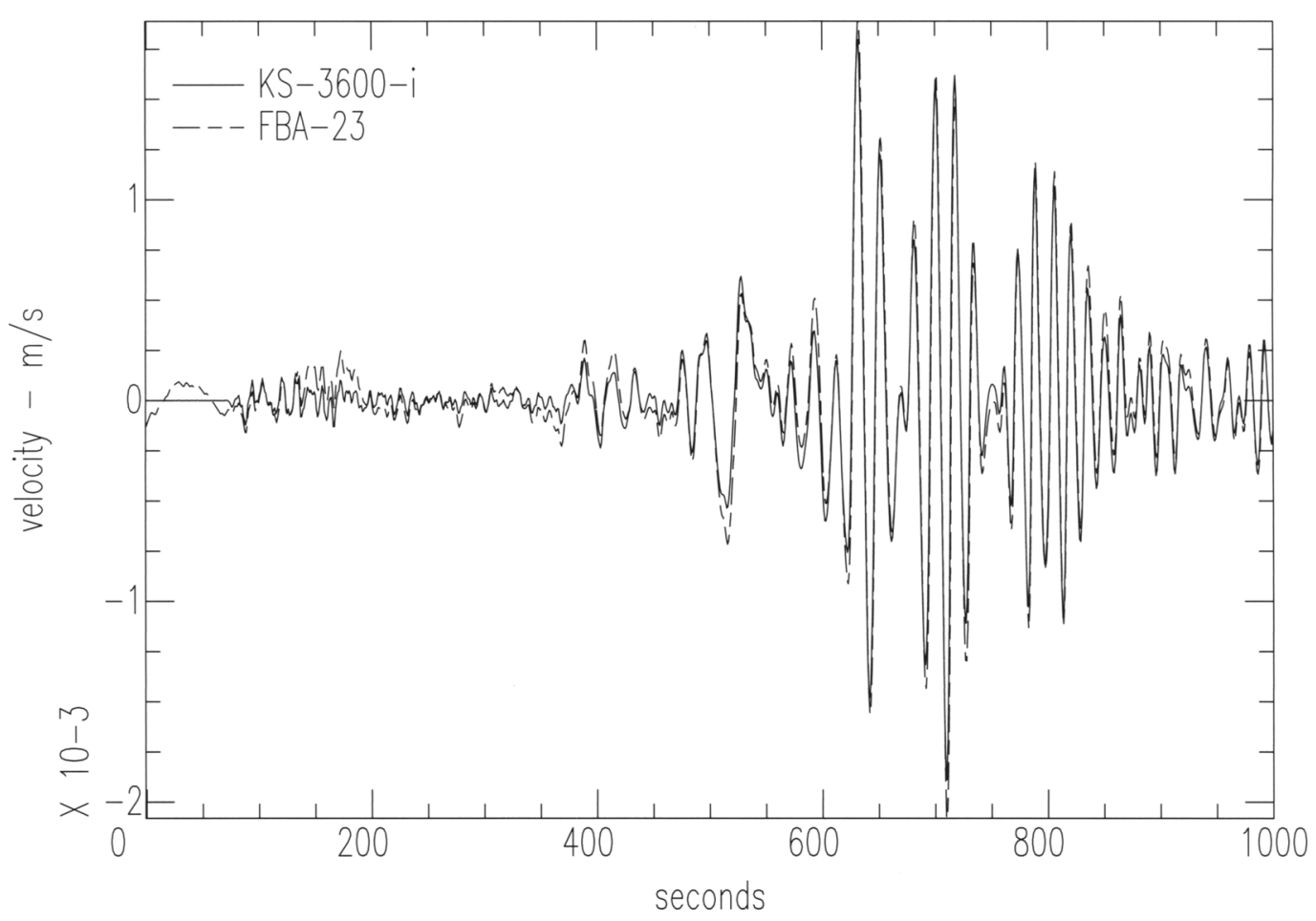

A Figure A1. Velocity time series of 1 sps integrated FBA-23 (dashed line: high-pass filter at $300 \mathrm{~s}$ ) and the $20 \mathrm{sps}$ KS-36000-i (solid line: decimated to $1 \mathrm{sps}$ ) recording of the Z component of the M 8.1 Balleny Island earthquake from IRIS-GSN Station SNZO at 2,900 km.

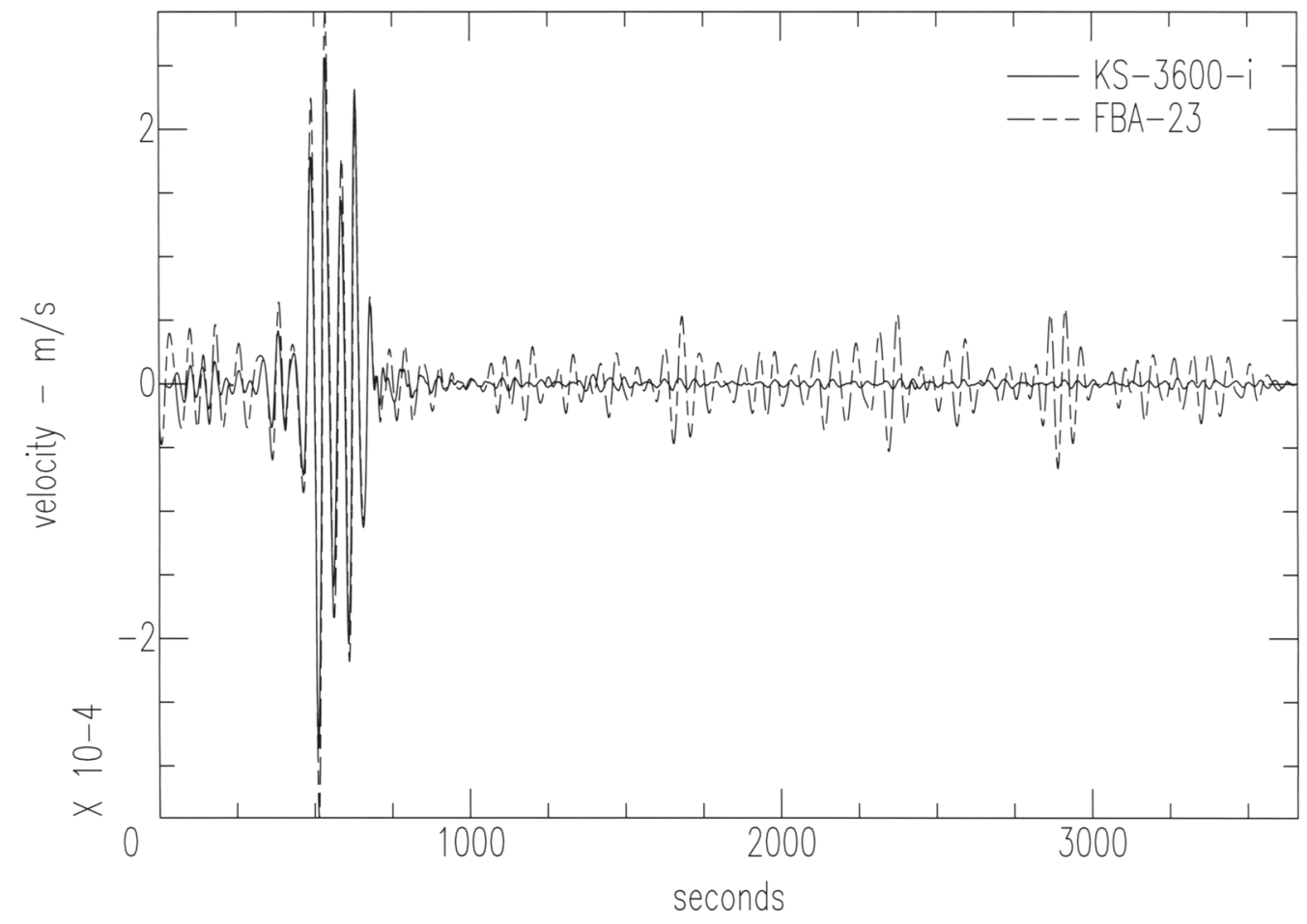

A Figure A2. As Figure A1, but with a band-pass from 37.5 to 75 seconds, clearly showing the FBA-23 recording (dashed line) is capable of recovering long-period motion up to 50 seconds. 


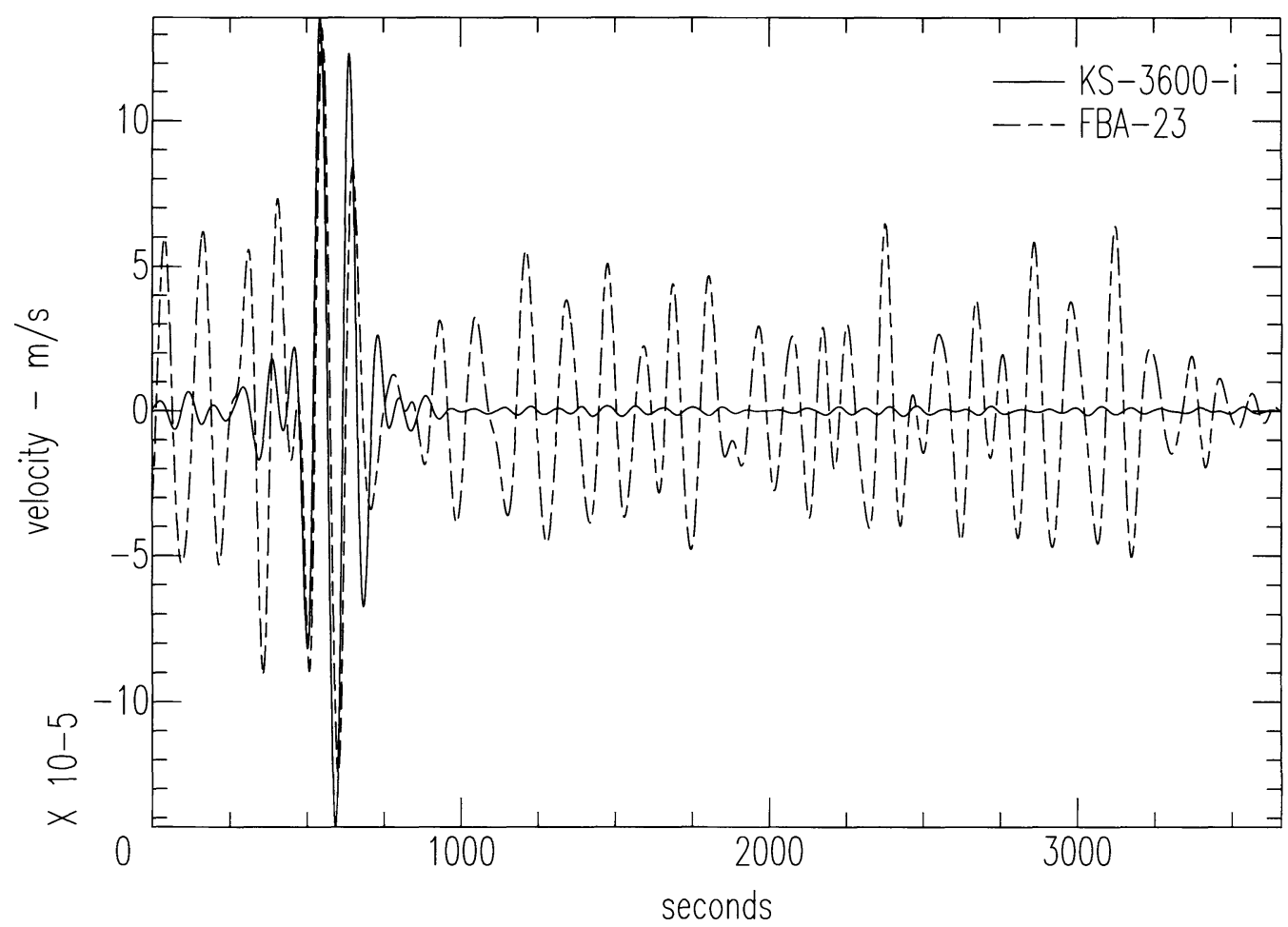

A Figure A3. As Figure A1, but with a band-pass from 75 to 150 seconds, showing the FBA-23 recording (dashed line) is not easily resolved above the instrument noise at these amplifications. 